\title{
Optical properties of composite restorations influenced by dissimilar dentin restoratives
}

\author{
Jovana Marjanovic ${ }^{a}$, Djordje N. Veljovic ${ }^{b}$, Jovana N. Stasic ${ }^{a}$, \\ Tatjana Savic-Stankovic ${ }^{a}$, Branka Trifkovic ${ }^{c}$, Vesna Miletic ${ }^{a, *}$ \\ a University of Belgrade, School of Dental Medicine, DentalNet Research Group, Rankeova 4, 11000 Belgrade, Serbia \\ ${ }^{b}$ University of Belgrade, Faculty of Technology and Metallurgy, Karnegijeva 4, 11120 Belgrade, Serbia \\ c University of Belgrade, School of Dental Medicine, Clinic for Prosthodontics, Rankeova 4, 11000 Belgrade, Serbia
}

\section{A R T I C L E I N F O}

\section{Article history:}

Received 26 October 2017

Received in revised form

16 January 2018

Accepted 16 January 2018

Keywords:

Color

Translucency

Biodentine

EverX

Hydroxyapatite

Layered composite restoration

Layering technique

Dentin restorative

Enamel layer

Composite

\begin{abstract}
A B S T R A C T
Objectives. To evaluate optical properties (color and translucency) of 'sandwich' restorations of resin-based composites and esthetically unfavorable dentin restoratives.

Methods. Cylindrical 'dentin' specimens ( $8 \mathrm{~mm}$ in diameter and $2 \mathrm{~mm}$ thick, $\mathrm{N}=5 /$ group) were prepared using EverX Posterior (GC), Biodentine (Septodont), experimental hydroxyapatite (HAP) or conventional composites (Gradia Direct Posterior, GC; Filtek Z250 and Filtek Z500, 3M ESPE). Capping 'enamel' layers were prepared using composites (Gradia Direct Posterior, Filtek Z250 or Z550) of A1 or A3 shade and the following thickness: 0.6, 1 or $2 \mathrm{~mm}$. Color $(\triangle \mathrm{E})$ and translucency parameter (TP) were determined using a spectrophotometer (VITA Easyshade Advance 4.0, VITA Zahnfabrik). Data were statistically analyzed using analysis of variance with Tukey's post-hoc tests $(\alpha=0.05)$.

Results. TP was greatly affected by layer thickness, whilst $\Delta \mathrm{E}$ depended on shade and layer thickness of the capping composite. HAP and Biodentine showed significantly lower TP and higher $\Delta \mathrm{E}$ (deviation from 'ideal white') than composites $(\mathrm{p}<0.05)$. Greater TP was seen in EverX_composite groups than in corresponding control groups of the same shade and thickness. TP of composites combined with Biodentine or HAP was below 2, lower than the corresponding control groups $(p<0.05)$. Within-group differences of $\Delta E$ were greatest in HAP_composite groups. EverX_Gradia and EverX_FiltekZ250 combinations showed the most comparable $\Delta \mathrm{E}$ with the control groups.

Significance. A $2 \mathrm{~mm}$ thick layer of composite covering dentin restoratives with unfavorable esthetics is recommended for a final 'sandwich' restoration that is esthetically comparable to a conventional, mono-composite control restoration.
\end{abstract}

@ 2018 The Academy of Dental Materials. Published by Elsevier Ltd. All rights reserved.

\section{Introduction}

High esthetic requirements present a challenge in restorative dentistry due to the complex structure of dental tissues.

\footnotetext{
* Corresponding author.

E-mail address: vesna.miletic@stomf.bg.ac.rs (V. Miletic). https://doi.org/10.1016/j.dental.2018.01.017
} 0109-5641/@ 2018 The Academy of Dental Materials. Published by Elsevier Ltd. All rights reserved.
This complexity is reflected in the specific micro-morphology, variable thickness, anisotropic and polychromatic nature as well as different composition of enamel and dentin [1,2]. The characteristic layout of enamel prisms and dentinal tubules and different amounts of organic substance cause differences in the optical parameters of these two tissues. Optical properties of contemporary composite restorations and natural 
Table 1 - Materials used in the study.

\begin{tabular}{|c|c|c|c|}
\hline Material (code) & Manufacturer & Type & Composition $^{\mathrm{a}}$ \\
\hline Filtek Z550 (Z550) & 3M ESPE, St. Paul, MN, USA & Nano-hybrid & $\begin{array}{l}\text { Matrix: BisGMA, UDMA, BisEMA, } \\
\text { PEGDMA, TEGMA } \\
\text { Filler type: surface-modified } \\
\text { zirconia/silica with a median particle } \\
\text { size of } 3 \mu \mathrm{m} \text { or less; } \\
\text { Non-agglomerated/non-aggregated } \\
20 \mathrm{~nm} \text { surface-modified silica particles } \\
\text { Filler content: } 82 \mathrm{wt} \%\end{array}$ \\
\hline Filtek Z250 (Z250) & 3M ESPE, St. Paul, MN, USA & Micro-hybrid & $\begin{array}{l}\text { Matrix: BisGMA, BisEMA, UDMA, } \\
\text { TEGDMA } \\
\text { Filler type: zirconia, silica } \\
\text { Particle size } 0.6 \mu \mathrm{m} \\
\text { Filler content: } 82 \mathrm{wt} \%\end{array}$ \\
\hline Gradia Direct Posterior (Gradia) & GC Corporation, Tokyo, Japan & Micro-hybrid & $\begin{array}{l}\text { Matrix: UDMA co-monomer matrix } \\
\text { Filler type: silica, prepolymerized } \\
\text { fillers, fluoroalumino-silicate glass } \\
\text { Particle size } 0.85 \mu \mathrm{m} \\
\text { Filler content: } 80 \mathrm{wt} \%\end{array}$ \\
\hline Biodentine (Biodentine) & $\begin{array}{l}\text { Septodont, } \\
\text { Saint-Maur-des-Fossés, France }\end{array}$ & Tricalcium-silicate cement & $\begin{array}{l}\text { Powder: tricalcium silicate, dicalcium } \\
\text { silicate, calcium carbonate, zirconium } \\
\text { oxide, iron oxide Liquid: calcium } \\
\text { chloride, hydrosoluble polymer, water }\end{array}$ \\
\hline Hydroxyapatite inserts (HAP) & Proprietary material & HAP based bioceramic & $\begin{array}{l}\text { Hydroxyapatite as the dominant } \\
\text { phase and low amount of } \alpha \text { - and } \\
\beta \text {-tricalcium phosphate phase }\end{array}$ \\
\hline EverX Posterior (EverX) & GC Corporation, Tokyo, Japan & $\begin{array}{l}\text { Fiber reinforced bulk-fill } \\
\text { composite }\end{array}$ & $\begin{array}{l}\text { Matrix: BisGMA, PMMA, TEGDMA } \\
\text { Filler type: Short E-glass fiber filler, } \\
\text { barium glass }\end{array}$ \\
\hline
\end{tabular}

teeth, despite differences in chemical composition and microstructure, contribute to excellent esthetic results [1-4].

A commonly accepted approach to material placement in clinical practice is a 'layered color matching' technique aimed at matching similar optical characteristics of the filling material and dental tissues in both anterior and posterior region $[5,6]$. Though color matching is more important in the anterior region, high esthetic demands require that the same approach is applied in the posterior region as well, warranting research data for such clinical situations, irrespective of the fact that they may be less frequent in daily practice.

For restoring Class I and II cavities, the layering technique of composite placement is used as a widely accepted 'gold standard' $[7,8]$. This technique ensures complete polymerization of composite materials, reduces polymerization shrinkage stress [9] but also allows matching optical properties of composite materials and dental tissues [1,4,7]. The color of the final restoration is not only influenced by the final composite layer [2-4], but is a result of optical properties of all layers combined [10].

The choice of shades is not always easy, considering that color of the composite changes after polymerization [11-14]. This change is affected by the initiator system [14,15] as well as the change in the refractive indices of the polymer relative to the fillers $[16,17]$. Furthermore, a number of factors may cause long-term color change, such as dehydration, chemical degradation, leakage, poor bonding and increased, surface roughness [18].
The 'layered color matching' technique is not suitable for the latest group of dental composites - sculptable 'bulk-fill' composites. Applied in 4-5 mm thick layers with a reduced number of available shades, these materials are intended for use as single-shaded materials, often for restoring the entire cavity in a single layer. An exception is fiber-reinforced EverX Posterior (GC) which requires a capping layer of a universal composite because glass fibers prevent polishability and hinder optimal esthetic results.

Another potentially compromising situation for highly esthetic composite restorations is dentin reconstruction in large cavities using non-esthetic restoratives, such as tricalcium silicate cements (e.g. Biodentine, Septodont) or hydroxyapatite (HAP) inserts [19]. There is very little information in the literature about esthetic properties of Biodentine when used as dentin restorative and its effect on the final restoration color $[20,21]$. Teeth restored with a 'sandwich' restoration of Biodentine and composite showed comparable color stability to composite restoration in vitro [21]. Conversely, perceptive coronal discoloration was found in a bovine tooth model following endodontic treatment [20]. Biodentine may be used to restore dentin in permanent restorations requiring a capping layer of resin-based composite.

Experimental HAP inserts have shown satisfactory bonding to dental composites and the ability to reduce polymerization shrinkage of insert-containing restorations [19]. Esthetic properties of restorations containing HAP inserts have not been tested before. The clinicians may face dilemmas related to the 
composite type, shade and thickness when used as a capping layer over dentin restoratives with challenging esthetics.

The aim of the study was to evaluate optical properties (color and translucency) of a composite restoration influenced by different dentin restoratives (conventional and bulk-fill composite, Biodentine and HAP). The null hypotheses were: (1) different dentin restoratives have no effect on color and translucency of the capping resin composite; (2) differences in 'enamel' layer shade, thickness and composite type have no effect on color and translucency of the final layered restoration.

\section{Materials and methods}

\subsection{Sample preparation}

Table 1 provides information on the materials used in this study. Circular molds, $8 \mathrm{~mm}$ in diameter and 0.6 or 1 or $2 \mathrm{~mm}$ deep, were used for sample preparation. Composite was placed in the mold on a microscope glass slide, covered with a transparent Mylar strip and light-cured using a polywave light-curing unit, Bluephase (Ivoclar Vivadent, Schaan, Liechtenstein), for $20 \mathrm{~s}$ at a standardized distance of $1 \mathrm{~mm}$. After curing, the samples were removed from the mold and stored dry at $37^{\circ} \mathrm{C}$ for $24 \mathrm{~h}$. 'Dentin' and 'enamel' samples were then subjected to measurement of optical properties of individual layers.

Biodentine samples were prepared following manufacturer's instructions. The powder was mixed with 5 drops of liquid in a capsule for $30 \mathrm{~s}$ using a mixing device (Silamat). The mixed cement was placed in the mold and allowed to set for $20 \mathrm{~min}$.

HAP samples were prepared from spherically agglomerated nanosized HAP powder, synthesized by hydrothermal method [19]. The synthesized HAP powder was isostatically pressed at $400 \mathrm{MPa}$ at $25^{\circ} \mathrm{C}$ for $30 \mathrm{~s}$, resulting in uniform cylindrical samples $8 \mathrm{~mm}$ in diameter and $2 \mathrm{~mm}$ thick. Approximately $0.18 \mathrm{~g}$ of powder was used for preparation of each specimen. The inserts were finally sintered at $1200^{\circ} \mathrm{C}$ for $2 \mathrm{~h}$, with a heating rate of $20^{\circ} \mathrm{C} / \mathrm{min}$. The properties of used HAP bioceramic inserts were shown previously [19].

For layered samples, 'dentin' layers of each dentin restorative material were first prepared in circular molds, $8 \mathrm{~mm}$ in diameter and $2 \mathrm{~mm}$ deep, followed by placement of respective 'enamel' composite layers (A1 or A3 shade). Each 'enamel' layer was applied on top of each 'dentin' layer and light-cured to simulate clinical conditions. The molds, $8 \mathrm{~mm}$ in diameter and $0.6 \mathrm{~mm}, 1 \mathrm{~mm}$ or $2 \mathrm{~mm}$ deep, were used for 'enamel' composite layer preparation. Each 'enamel' composite layer was covered with a transparent Mylar strip and light-cured with the same LED light-curing unit to create a highly glossy surface and prevent an oxygen inhibition layer, eliminating the need for further polishing.

\subsection{Color and translucency measurements}

Color and translucency were measured using a spectrophotometer VITA Easyshade ${ }^{\circledR}$ Advance 4.0 (VITA Zahnfabrik, Bad Säckingen, Germany) against a white and black background. The unit was calibrated following manufacturer's instructions.
The upper, irradiated surface of each specimen was measured. Each specimen was measured 4 times in total (twice against a white and twice against a black background). The probe tip was placed directly on the specimen surface. A custom-made shield was attached to the Easyshade ${ }^{\circledR}$ tip to create a dark environment and eliminate ambient light prior to and during measurements.

Color was measured relative to the standard illuminant D65. The obtained color values were expressed according to the CIEL*a*b* color system. As no before and after measurements were done in this study, color $(\Delta E)$ of each specimen was determined in the 3D color coordinate system as a deviation from 'ideal white' [22] and calculated as:

$\Delta E=\sqrt{\Delta L^{2}+\Delta a^{2}+\Delta b^{2}}$

with the color coordinates over the white background:

$\Delta \mathrm{L}=\mathrm{L}^{*}$ of the specimen $-\mathrm{L}^{*}$ standard to ideally white color (100)

$\Delta a=a^{*}$ of the specimen $-a^{*}$ standard to ideally white color (0)

$\Delta b=b^{*}$ of the specimen $-b^{*}$ standard to ideally white color (0)

Translucency parameter (TP) was calculated using the formula:

$\mathrm{TP}=\sqrt{(\mathrm{L} 1-\mathrm{L} 2)^{2}+(a 1-a 2)^{2}+(b 1-b 2)^{2}}$

where 1 is the respective coordinate against the black and 2 against the white background.

\subsection{Statistical analysis}

The data were statistically analyzed in the statistical software Minitab 16 (Minitab Inc. State College, PA, USA). One-way ANOVA with Tukey's post-hoc test was used to test differences in $\triangle \mathrm{E}$ and TP within each composite group as well as betweencomposite groups of the same shade and thickness. The level of significance was set at $\alpha=0.05$.

\section{Results}

Table 2 presents mean CIEL*a*b* values of color coordinates of the tested materials. All composite specimens had higher $\mathrm{L}^{*}$ (lightness) values than HAP and especially Biodentine. Also, b* values of composites were generally higher than those of HAP but were comparable with Biodentine in A1 or thin A3 samples. $L^{*}$ values were highest for $1 \mathrm{~mm}$ thick samples whilst $b^{*}$ values increased with thickness and were highest in $2 \mathrm{~mm}$ thick samples. CIEL*a*b* values could not be measured for EverX.

Figs. 1-3 present TP values for individual materials and their combined use in layered samples. TP was greatly affected by layer thickness, more than by the shade or composite brand, i.e. with increasing thickness TP values decreased in all groups. TP was similar in samples of different shades but the same thickness within each composite group ( $p>0.5)$. HAP and Biodentine showed lower TP values than all of the tested composites $(\mathrm{p}<0.05)$.

As for layered samples, TP values in the control groups decreased with increasing layer thickness irrespective of the shade. Within each composite, both A1 and A3 shades 


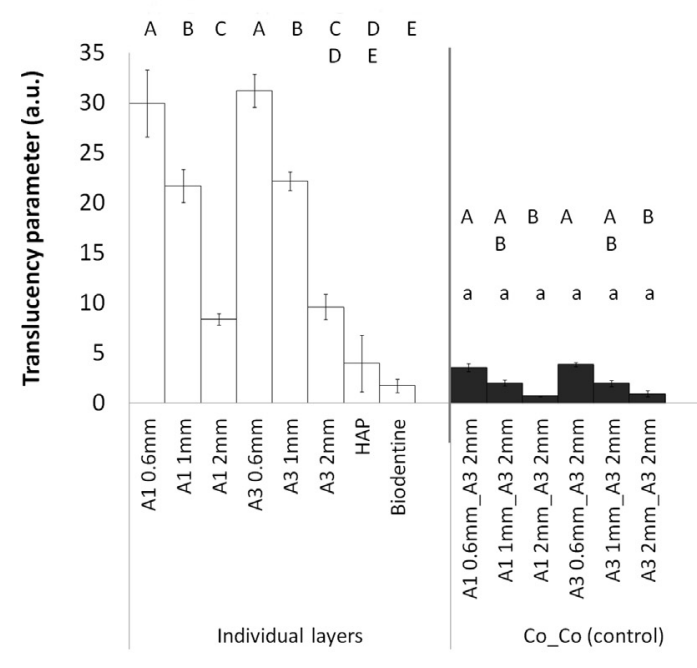

\section{Filtek Z550}

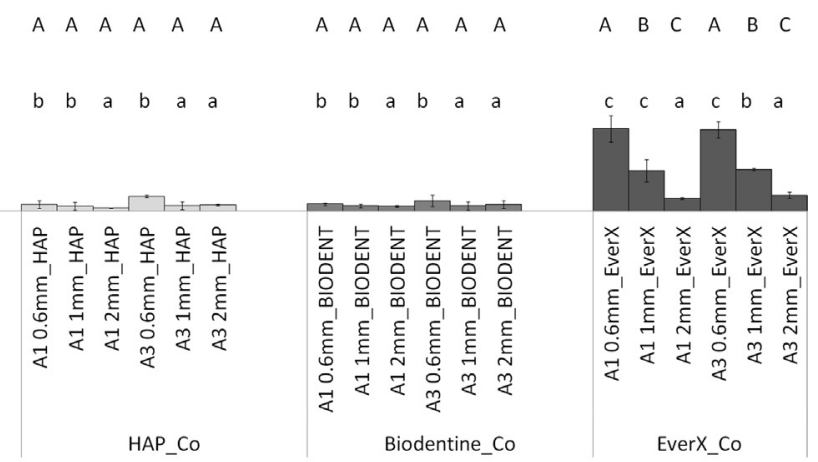

Layered samples ('dentin'_'enamel' layers)

Fig. 1 - Translucency (TP) of individual materials and of layered restorations with Filtek Z550 used as a capping layer. Upper-case letters indicate within-group differences, lower-case letters indicate between-group differences of materials with the same shade and thickness $(p<0.05)$.

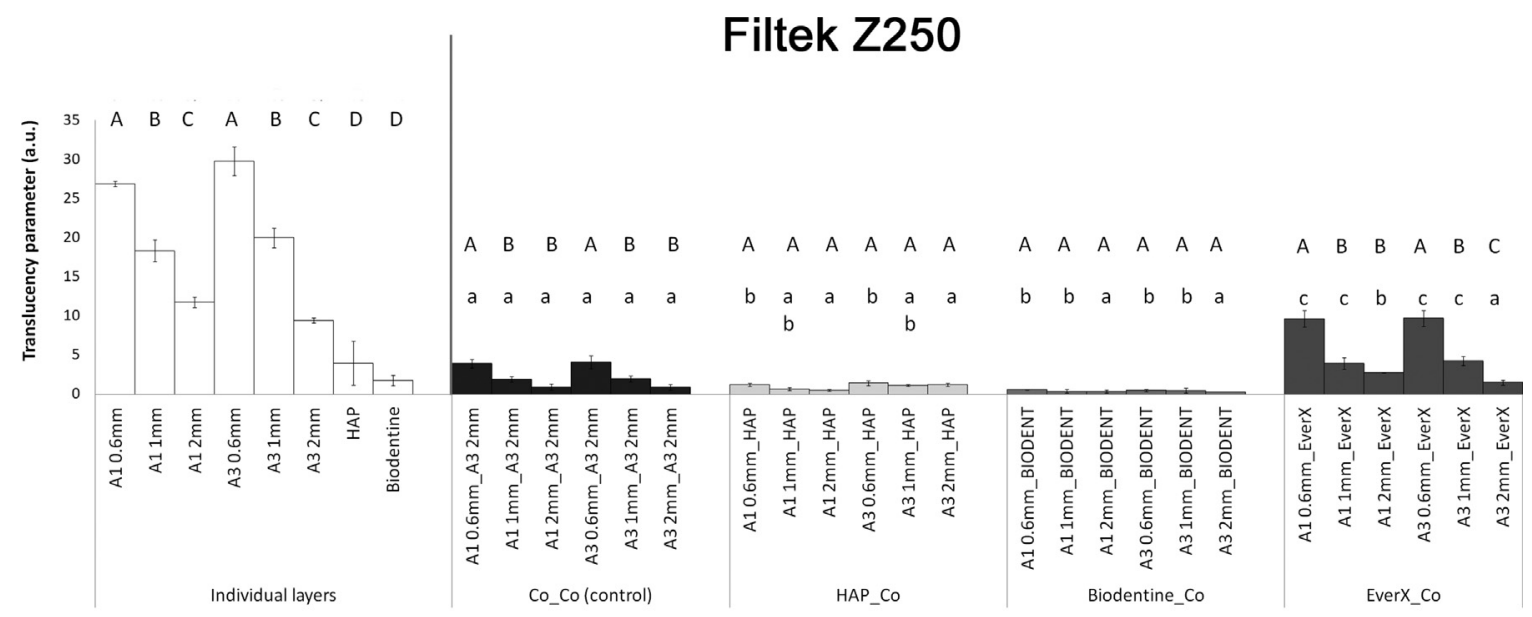

Layered samples ('dentin'_'enamel' layers)

Fig. 2 - Translucency (TP) of individual materials and of layered restorations with Filtek Z250 used as a capping layer. Letters indicating statistical differences as in Fig. 1.

of samples of the same thickness exhibited similar TP $(p>0.05)$. The same trend was found in the group EverX ('dentin')_Gradia/Z550/Z250 ('enamel'). However, variations between 'enamel' layer thicknesses were greater than in the control group. An exception is the A3 shade of Z250 at $2 \mathrm{~mm}$ 'enamel' layer thickness combined with EverX which showed lower TP than the corresponding group of Z250 A1 shade $(p<0.05)$. For each composite, greater TP was seen in EverX groups than in the control groups of the same shade and thickness $(p<0.05)$. Generally, EverX with 'enamel' composite layer thickness of $2 \mathrm{~mm}$ produced comparable TP to the corresponding control composite group ( $p>0.05)$. TP values of the tested composites in combination with Biodentine or
HAP were below 2 with no significant influence of composite shade and thickness and were generally lower than the corresponding control groups.

Figs. 4-6 present $\Delta \mathrm{E}$ values for individual materials and their combined use in layered samples. $\Delta \mathrm{E}$ has shown the opposite trend of TP but color was affected by both composite shade and thickness i.e. with increasing thickness and in darker shades, $\Delta \mathrm{E}$ also increased suggesting greater deviation from 'ideal white'. HAP and Biodentine had significantly higher $\Delta \mathrm{E}$ values than any composite group $(\mathrm{p}<0.05)$.

As for layered samples, generally both shade and layer thickness affected $\Delta \mathrm{E}$ of the 'enamel' composite layer 


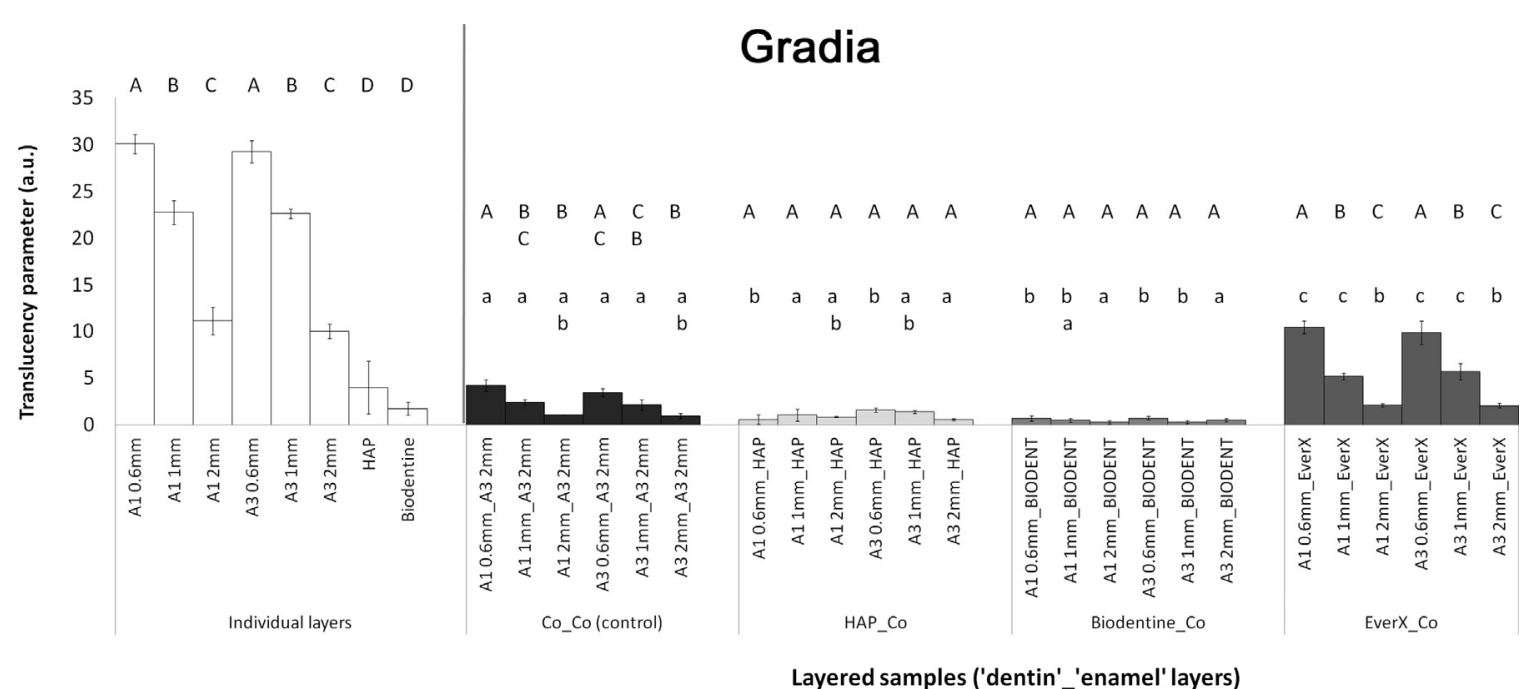

Fig. 3 - Translucency (TP) of individual materials and of layered restorations with Gradia used as a capping layer. Letters indicating statistical differences as in Fig. 1.

with all dentin restoratives. The highest $\Delta \mathrm{E}$ values i.e. the darker-colored samples were observed for $2 \mathrm{~mm}$ thick layers of composites A3 shade, irrespective of the dentin restorative $(p<0.05)$. The biggest differences in $\Delta E$ within a particular group of dentin restorative were found in HAP_composite groups. The most comparable $\Delta \mathrm{E}$ values between experimental and corresponding control groups were found for EverX_Gradia and EverX_Z250 combinations. HAP and Biodentine combined with the tested composites had roughly the same number of comparable pairs with the corresponding control groups. Regarding layer thickness, the most comparable pairs with the corresponding control group were found for $2 \mathrm{~mm}$ thick 'enamel' composite layers irrespective of the dentin restorative followed by $1 \mathrm{~mm}$ and $0.6 \mathrm{~mm}$ thick layers, respectively.

\section{Discussion}

The present results showed differences in optical properties of the final composite restorations related to different dentin restoratives as well as 'enamel' composite layer shade, thickness and composite type. Therefore, all null hypotheses were rejected.

A broad approach in this study aimed at studying the effects of several important clinical parameters such as material type, shade and layer thickness as well as the effect of dentin restorative on optical properties of final composite restorations. We selected three composite brands to represent different materials in terms of filler content and the organic matrix. Microhybrid or nanohybrid, BisGMA-based or nonBisGMA-based composites were included in the study. The tested composites are based on a universal or standard Vita

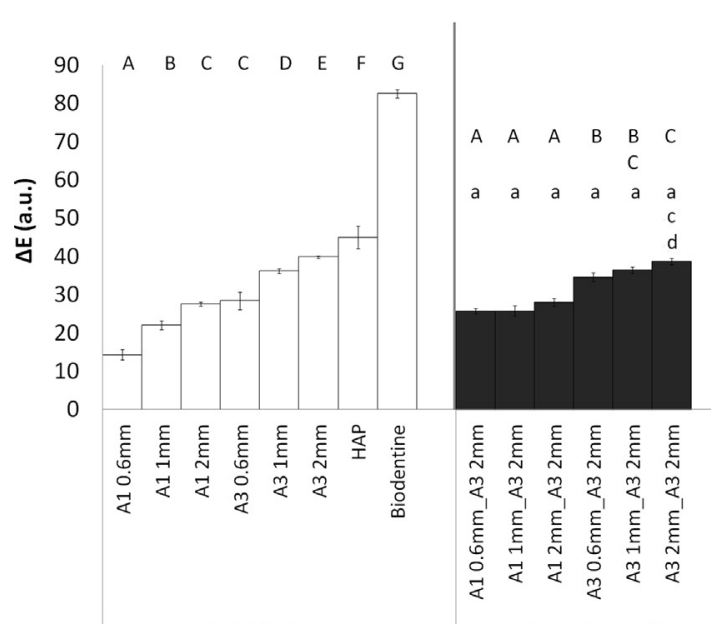

Individual layers

Co_Co (control)

\section{Filtek Z550}

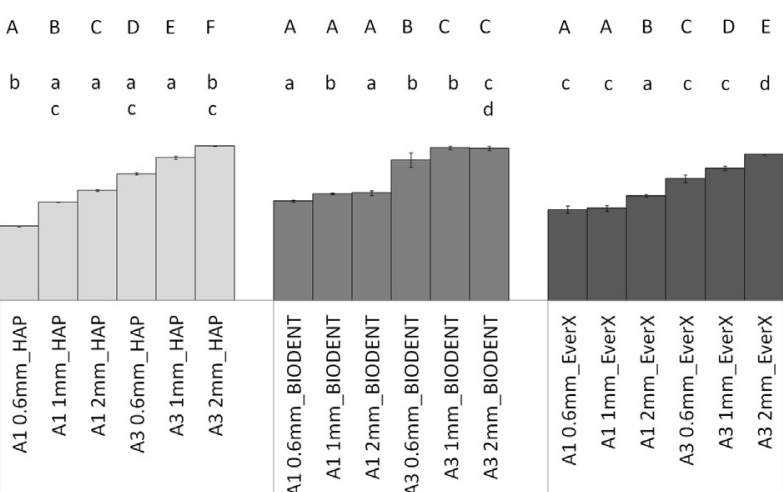

HAP_Co
Biodentine Co

EverX Co

Layered samples ('dentin'_'enamel' layers)

Fig. 4 - Color deviation from 'ideal white' $(\Delta E)$ values for individual and layered samples when Filtek Z550 was combined with different dentin restoratives. Letters indicating statistical differences as in Fig. 1. 


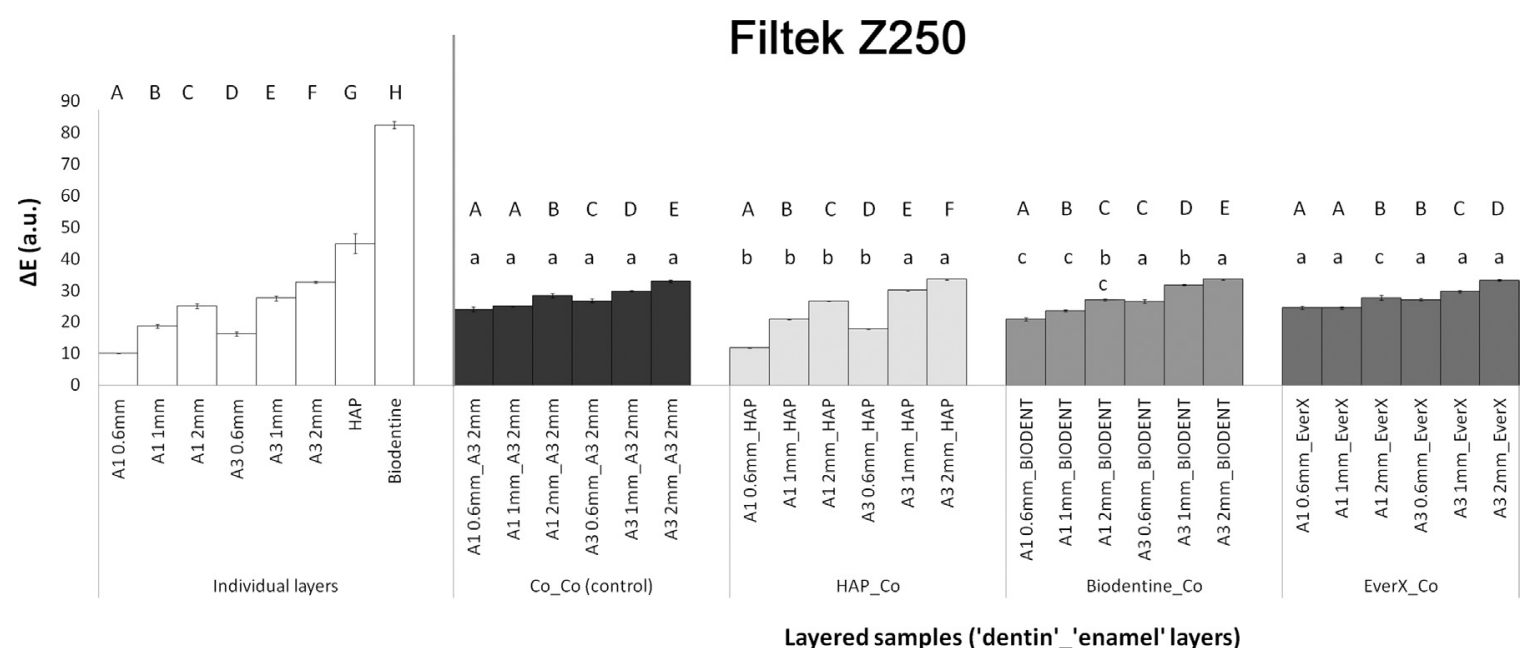

Fig. 5 - Color deviation from 'ideal white' $(\Delta E)$ values for individual and layered samples when Filtek Z250 was combined with different dentin restoratives. Letters indicating statistical differences as in Fig. 1.

shade guide. Though color properties of $\mathrm{A} 1$ and $\mathrm{A} 3$ are not the most different in the classical Vita shade guide, these shades were selected because of their widespread use in everyday clinical practice, $A 1$ representing a lighter and $A 3$ representing a darker shade. Dentin restoratives with highly unfavorable esthetics, a commercially available silicate-based cement and an experimental HAP, and a fiber-reinforced composite with less challenging esthetics than the previous two materials were compared to a control, conventional composite. The ultimate goal was to ascertain whether a certain thickness of a capping composite layer of frequently used shades could mimic the unfavorable esthetics of dentin restoratives.

Color was determined using a clinical spectrophotometer as these are considered reliable not only in clinical applications, but also for research purposes in evaluating color interactions of human teeth and dental materials [23]. Vita Easyshade was used in the present study as a confirmation was obtained from the manufacturer that this spectropho- tometer may be used to compare shades of equally shaped specimens of any material in the Vita color range.

Color $(\Delta \mathrm{E})$ values are usually determined by subtracting values between groups or before-after measurements [11,24,25]. As no before-after measurements were done in the present study, a new approach was used to position the color of each sample in the color coordinate system when there is only one measurement i.e. $\Delta \mathrm{E}$ was measured relative to an 'ideal white' standard threshold characterized by $\mathrm{L}^{*}=100, \mathrm{a}^{*}=0$ and $\mathrm{b}^{*}=0$ [22]. This also allowed a number of within-group and betweengroup comparisons. Further comparison between groups of interest may be accomplished by simple subtracting $\Delta \mathrm{E}$ values to yield clinical acceptability of any such difference $(\Delta E>3.3)$.

Color may be determined using CIEL*a*b* or CIEDE2000 formulas recommended by the International Commission on Illumination (CIE). Though CIEDE2000 is a more recent formula, both are frequently used and still compared in recent dental studies $[26,27]$.

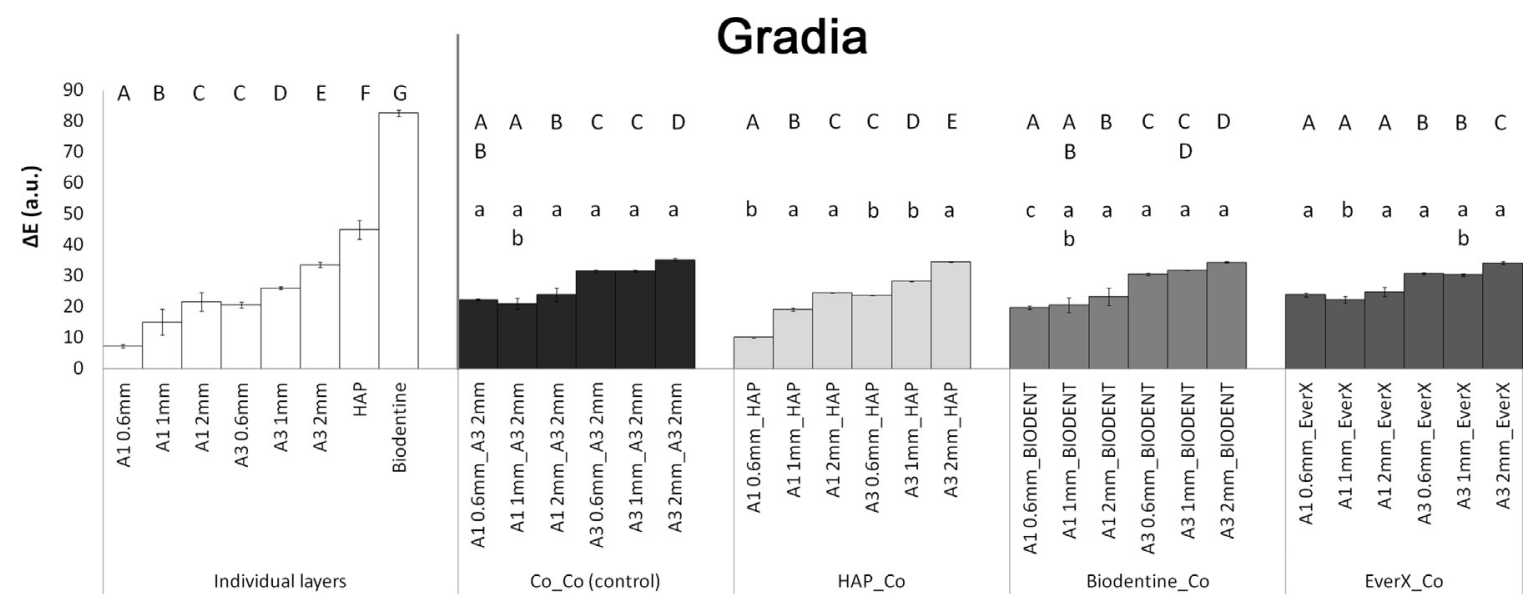

Layered samples ('dentin'_'enamel' layers)

Fig. 6 - Color deviation from 'ideal white' $(\Delta E)$ values for individual and layered samples when Gradia was combined with different dentin restoratives. Letters indicating statistical differences as in Fig. 1. 
Table 2 - Mean CIEL*a*b* values of the tested materials.

\begin{tabular}{llcc} 
Group & $\mathrm{L}^{*}$ & $\mathrm{a}^{*}$ & $\mathrm{~b}^{*}$ \\
\hline Filtek Z550 A1 $(0.6 \mathrm{~mm})$ & 81.44 & -1.95 & 10.85 \\
Filtek Z550 A1 $(1 \mathrm{~mm})$ & 85.54 & -1.58 & 17.37 \\
Filtek Z550 A1 $(2 \mathrm{~mm})$ & 80.08 & -1.76 & 18.89 \\
Filtek Z550 A3 $(0.6 \mathrm{~mm})$ & 75.57 & -1.56 & 19.98 \\
Filtek Z550 A3 $(1 \mathrm{~mm})$ & 81.68 & 0.08 & 29.03 \\
Filtek Z550 A3 $(2 \mathrm{~mm})$ & 76.28 & 1.13 & 30.59 \\
Filtek Z250 A1 $(0.6 \mathrm{~mm})$ & 80.21 & -2.03 & 2.86 \\
Filtek Z250 A1 $(1 \mathrm{~mm})$ & 81.01 & -1.73 & 11.74 \\
Filtek Z250 A1 $(2 \mathrm{~mm})$ & 75.79 & -1.42 & 12.43 \\
Filtek Z250 A3 $(0.6 \mathrm{~mm})$ & 72.91 & -2.02 & 7.95 \\
Filtek Z250 A3 $(1 \mathrm{~mm})$ & 78.10 & -0.22 & 19.23 \\
Filtek Z250 A3 $(2 \mathrm{~mm})$ & 74.38 & 0.44 & 20.24 \\
Biodentine & 18.94 & 3.09 & 13.46 \\
Gradia Direct A1 $(0.6 \mathrm{~mm})$ & 79.46 & -1.88 & 3.16 \\
Gradia Direct A1 $(1 \mathrm{~mm})$ & 85.13 & -1.98 & 10.35 \\
Gradia Direct A1 $(2 \mathrm{~mm})$ & 81.13 & -2.13 & 12.53 \\
Gradia Direct A3 $(0.6 \mathrm{~mm})$ & 75.60 & -0.80 & 13.92 \\
Gradia Direct A3 $(1 \mathrm{~mm})$ & 79.69 & 0.12 & 19.27 \\
Gradia Direct A3 $(2 \mathrm{~mm})$ & 74.53 & 1.54 & 21.95 \\
HAP & 70.81 & 0.12 & 5.61 \\
\hline
\end{tabular}

The most important finding is that, irrespective of dentin restorative and composite type and shade, a capping layer thickness of $2 \mathrm{~mm}$ is sufficient for a final 'sandwich' restoration that is esthetically comparable to a conventional, mono-composite control restoration.

The data suggest substantial difference in TP of individual dentin restoratives and combined 'sandwich' restorations of such materials and capping composite layers (Figs. 1-3). Similar discrepancy was observed in $\triangle \mathrm{E}$ especially of HAP and Biodentine alone and combined with capping composites (Figs. 4-6). The fact that capping composite layers considerably changed optical properties of a layered restoration indicate the potential of microhybrid and nanohybrid composites to obtain favorable esthetic results even with dentin restoratives of extreme optical properties.

Translucency of the tested composites without a dentin restorative was greatly affected by layer thickness with an inverse relationship between these two parameters i.e. with increased layer thickness its TP decreased. Low translucency of a composite material in the posterior region is important for mimicking unfavorable discoloration in the dentin area or, in this case, dentin restoratives with unfavorable esthetics.

A distinct effect of layer thickness on TP was previously reported for enamel shades of a microhybrid Gradia (GC) and a nanocomposite Filtek Supreme (3M) $[28,29]$. In the present study, all tested composite shades may be classified as universal as no specific enamel/dentin or opaque variations were used. These findings indicate that the effect of composite thickness on translucency seems to generally hold for dental composites. The clinical significance of this notion lies in the fact that not only commercial composites differ in optical properties but they are also differently labeled by manufacturers, leading to potential clinical dilemmas as to how different materials would perform in this respect. The clinicians should be aware that, irrespective of the composite they use, the thicker the composite layer the less translucent (more opaque) it appears. Thinner 'enamel' layers are more affected by the color of the underlying 'dentin' layer or inherent discolorations in the tooth tissues.

Color was affected by both composite shade and thickness as increased thickness of darker shaded composite resulted in darker colored final restorations. Previous studies also reported that composite shade and thickness affect color of layered composite restorations but focused only on combinations of 'enamel' and 'dentin' composite restoratives [7,30]. The present study reports on an even greater effect of dentin restoratives based on a calcium silicate cement, HAP or fiberreinforced composite on the color of the capping composite layer of various shade and thickness. The thinnest capping layer $(0.6 \mathrm{~mm})$ of a lighter shade (A1) resulted in the greatest color discrepancy from the control group when combined with the tested dentin restoratives. It becomes clear that dentin restoratives of unfavorable esthetics are limited to the posterior region. The present results suggest that in such cases unfavorable esthetics of underlying dentin restoratives may be mimicked by capping composites of 1-2 mm thick layers. Large defects in anterior teeth should be restored with composite materials as highly esthetic demands in anterior region are more likely met following an all-composite approach than using 'sandwich' restorations of dissimilar materials.

$\mathrm{TP}$ and $\Delta \mathrm{E}$ could not be calculated for EverX because CIEL*a*b* values could not be measured even when different backgrounds were used. In a previous study, TP was determined for Xenius, a predecessor of EverX using a different spectrophotometer [31]. It was found to have higher translucency than a number of flowable and sculptable bulk-fill composites and a nanohybrid conventional control which was likely a contributing factor to increased depth of cure of this material [31]. In the present study, a greater range of TP values of layered samples in EverX_composite groups compared to other dentin restoratives could be associated with increased translucency of this fiber-reinforced composite. About 5 times greater translucency was found for final EverX-containing restorations with $0.6 \mathrm{~mm}$ than $2 \mathrm{~mm}$ capping layer thickness, irrespective of composite type and shade. A layer thickness of $2 \mathrm{~mm}$ of the capping composite layer was generally sufficient to maintain the overall translucency of the restoration comparable to the control group.

The effect of EverX on color of the capping composite layer was less pronounced than on translucency. The color of 'sandwich' restorations of EverX and microhybrid composites Gradia and Z250 was mostly similar to corresponding control groups of mono-composite restorations irrespective of shade and layer thickness. When combined with EverX, the nanohybrid Z550 showed slightly more discrepancies in color comparison to control groups than did Z250 and Gradia. It seems that filler size rather than resin composition played a role in color matching of the two microhybrid composites (Gradia and Z250) whilst Z250 and Z550, of virtually the same organic matrix, differed in filler size. It was previously reported that even relatively small differences in filler size may affect light reflectivity and scattering coefficient [32].

Biodentine and HAP resulted in highly opaque 'sandwich' restorations with different composites with TP values below 2 , even though composites alone exhibited TP values in the range of 10-30. As was seen with EverX, the effect on color was less pronounced than on translucency. Very thin layers 
especially of light shade were highly affected by Biodentine and HAP. Literature lacks data for comparison, but based on the present results, capping layer thickness below $1 \mathrm{~mm}$ is not recommended for any composite and shade. A composite layer of $2 \mathrm{~mm}$ should be sufficient for best esthetic results in 'sandwich' restorations with Biodentine or HAP as dentin restoratives.

An overview of CIEL*a*b* values for the tested materials showed that composites' appearance is determined by high lightness $\left(\mathrm{L}^{*}\right)$ and yellowish $\left(\mathrm{b}^{*}\right)$ color values. As would be expected, darker composite shades are characterized by lower lightness and higher yellowish color than the lighter shade of the same composite. Biodentine's grayish appearance to the naked eye may be associated with a very low lightness value. HAP appears white due to high lightness and low other color values. Interestingly, $\mathrm{L}^{*}$ values were highest in $1 \mathrm{~mm}$ thick specimens. Lower $L^{*}$ values in thinner $(0.6 \mathrm{~mm})$ specimens could be due to the fact that mean $\mathrm{L}^{*}$ values were determined based on measurements against the white and black background. In very thin specimens the effect of black background may have intensified especially due to greater translucency of these specimens.

\section{Conclusion}

In general, a $2 \mathrm{~mm}$ thick layer of universal microhybrid or nanohybrid composite is recommended for covering dentin restoratives with unfavorable esthetics, resulting in a final 'sandwich' restoration that is esthetically comparable to a conventional, mono-composite control restoration. Depending on a composite and dentin restorative type, $1 \mathrm{~mm}$ thick layers may be sufficient for the same results. However, capping layers thinner than $1 \mathrm{~mm}$ especially of light shades are not recommended for esthetically challenging dentin restoratives such as Biodentine, EverX or HAP-like materials. Clinicians should be aware that composite thickness greatly affects translucency of the restoration in an inverse relationship. In areas requiring highly translucent appearance, slight changes in composite thickness, much more than shade or material type, may affect the final outcome.

\section{Funding}

This work was supported by the Ministry of Education, Science and Technological Development, Republic of Serbia [grant numbers ON172007, III45019].

\section{Acknowledgements}

The authors would like to thank 3M ESPE, GC and Septodont for generous donations of the materials used in this study.

\section{REFERENCES}

[1] Dietschi D. Optimising aesthetics and facilitating clinical application of free-hand bonding using the 'natural layering concept'. Br Dent J 2008;204:181-5.
[2] Villarroel M, Fahl Jr N, de Sousa AM, de Oliveira Jr OB. Direct esthetic restorations based on translucency and opacity of composite resins. J Esthet Restor Dent 2011;23:73-87.

[3] Corciolani G, Vichi A, Louca C, Ferrari M. Influence of layering thickness on the color parameters of a ceramic system. Dent Mater 2010;26:737-42.

[4] Schmeling M, Meyer-Filho A, Andrada MAC, Baratieri LN. Chromatic influence of value resin composites. Oper Dent 2010;35:44-9.

[5] Deliperi S, Bardwell DN. Multiple cuspal-coverage direct composite restorations: functional and esthetic guidelines. J Esthet Restor Dent 2008;20:300-8, discussion 9-12.

[6] Devoto W, Saracinelli M, Manauta J. Composite in everyday practice: how to choose the right material and simplify application techniques in the anterior teeth. Eur J Esthet Dent 2010;5:102-24.

[7] Khashayar G, Dozic A, Kleverlaan CJ, Feilzer AJ, Roeters J. The influence of varying layer thicknesses on the color predictability of two different composite layering concepts. Dent Mater 2014;30:493-8.

[8] Park J, Chang J, Ferracane J, Lee IB. How should composite be layered to reduce shrinkage stress: incremental or bulk filling. Dent Mater 2008;24:1501-5.

[9] Ferracane JL. Resin composite—state of the art. Dent Mater 2011;27:29-38

[10] Lee YK, Powers JM. Calculation of colour resulting from composite/compomer layering techniques. J Oral Rehabil 2004;31:1102-8.

[11] Celik EU, Aladag A, Turkun LS, Yilmaz G. Color changes of dental resin composites before and after polymerization and storage in water. J Esthet Restor Dent 2011;23:179-88.

[12] del Mar Perez M, Saleh A, Pulgar R, Paravina RD. Light polymerization-dependent changes in color and translucency of resin composites. Am J Dent 2009;22:97-101.

[13] Kim IJ, Lee YK. Changes in color and color parameters of dental resin composites after polymerization. J Biomed Mater Res B Appl Biomater 2007;80:541-6.

[14] Sabatini C, Campillo M, Aref J. Color stability of ten resin-based restorative materials. J Esthet Restor Dent 2012;24:185-99.

[15] Shin DH, Rawls HR. Degree of conversion and color stability of the light curing resin with new photoinitiator systems. Dent Mater 2009;25:1030-8.

[16] Miletic V, Jakovljevic N, Manojlovic D, Marjanovic J, Rosic AA, Dramićanin MD. Refractive indices of unfilled resin mixtures and cured composites related to color and translucency of conventional and low-shrinkage composites. J Biomed Mater Res B Appl Biomater 2017;105:7-13.

[17] Shortall AC, Palin WM, Burtscher P. Refractive index mismatch and monomer reactivity influence composite curing depth. J Dent Res 2008;87:84-8.

[18] Lee Y-K, Yu B, Lim H-N, Lim JI. Difference in the color stability of direct and indirect resin composites. J Appl Oral Sci 2011;19:154-60.

[19] Lezaja M, Veljovic D, Manojlovic D, Milosevic M, Mitrovic N, Janackovic Dj, et al. Bond strength of restorative materials to hydroxyapatite inserts and dimensional changes of insert-containing restorations during polymerization. Dent Mater 2015;31:171-81.

[20] Beatty H, Svec T. Quantifying coronal tooth discoloration caused by Biodentine and EndoSequence Root Repair Material. J Endod 2015;41:2036-9.

[21] Valles M, Roig M, Duran-Sindreu F, Martínez S, Mercadé M. Color stability of teeth restored with Biodentine: a 6-month in vitro study. J Endod 2015;41:1157-60.

[22] Manojlovic D, Dramicanin MD, Lezaja M, Pongprueksa P, Van Meerbeek B, Miletic V. Effect of resin and photoinitiator on color, translucency and color stability of conventional and 
low-shrinkage model composites. Dent Mater 2016;32:183-91.

[23] Chu SJ, Trushkowsky RD, Paravina RD. Dental color matching instruments and systems: review of clinical and research aspects. J Dent 2010;38(Suppl. 2):e2-16.

[24] Fonseca AS, Labruna Moreira AD, de Albuquerque PP, de Menezes LR, Pfeifer CS, Schneider LF. Effect of monomer type on the CC degree of conversion, water sorption and solubility, and color stability of model dental composites. Dent Mater 2017;33:394-401.

[25] Perez MM, Ghinea R, Ugarte-Alvan LI, Pulgar R, Paravina RD. Color and translucency in silorane-based resin composite compared to universal and nanofilled composites. J Dent 2010;38:E110-6.

[26] Pecho OE, Ghinea R, Alessandretti R, Pérez MM, Della Bona A. Visual and instrumental shade matching using CIELAB and CIEDE2000 color difference formulas. Dent Mater 2016;32:82-92.

[27] Gomez-Polo C, Portillo Munoz M, Lorenzo Luengo MC, Vicente P, Galindo P, Martín Casado AM. Comparison of the CIELab and CIEDE2000 color difference formulas. J Prosthet Dent 2016;115:65-70.
[28] Kamishima N, Ikeda T, Sano H. Color and translucency of resin composites for layering techniques. Dent Mater J 2005;24:428-32.

[29] Kamishima N, Ikeda T, Sano H. Effect of enamel shades on color of layered resin composites. Dent Mater J 2006;25:26-31.

[30] Friebel M, Pernell O, Cappius HJ, Helfmann J, Meinke MC. Simulation of color perception of layered dental composites using optical properties to evaluate the benefit of esthetic layer preparation technique. Dent Mater 2012;28:424-32.

[31] Miletic V, Pongprueksa P, De Munck J, Brooks NR, Van Meerbeek B. Curing characteristics of flowable and sculptable bulk-fill composites. Clin Oral Investig 2017;21:1201-12.

[32] Lim YK, Lee YK, Lim BS, Rhee SH, Yang HC. Influence of filler distribution on the color parameters of experimental resin composites. Dent Mater 2008;24:67-73. 